\title{
1 How to improve threatened species management: an Australian perspective
}

2

3 Published: Journal of Environmental Management, 223: 668-675.

4 https://www.sciencedirect.com/science/article/pii/S0301479718307369

6 Authors: Scheele, B.C. ${ }^{* a, b}$, Legge, S. ${ }^{\mathrm{a}, \mathrm{b}}$, Armstrong, D.P. ${ }^{\mathrm{c}}$, Copley, P. ${ }^{\mathrm{d}}$, Robinson, N. ${ }^{\mathrm{a}, \mathrm{b}}$, 7 Southwell, D. ${ }^{\text {b, e }}$, Westgate, M.J. ${ }^{a}$ \& Lindenmayer, D.B. ${ }^{\text {a, b }}$

9 a Fenner School of Environment and Society, The Australian National University, Canberra, 10 Australia

$11{ }^{\mathrm{b}}$ National Environmental Science Programme, Threatened Species Recovery Hub, Australia

$12{ }^{\mathrm{c}}$ Wildlife Ecology Group, Massey University, Palmerston North, New Zealand

$13{ }^{\mathrm{d}}$ Parks and Regions, Department of Environment, Water and Natural Resources, South

14 Australia, Australia

$15{ }^{\mathrm{e}}$ Quantitative and Applied Ecology Group, School of BioSciences, University of Melbourne, 16 Victoria, Australia

$18 *$ Corresponding author: Ben Scheele (ben.scheele@anu.edu.au)

19 Building 141, Fenner School of Environment and Society, Linnaeus Way, Acton, ACT 2601, 20 Australia

Article type: Review

\section{Abstract}

Targeted threatened species management is a central component of efforts to prevent species extinction. Despite the development of a range of management frameworks to improve 
conservation outcomes over the past decade, threatened species management is still commonly characterised as ad hoc. Although there are notable successes, many management programs are ineffective, with relatively few species experiencing improvements in their conservation status. We identify underlying factors that commonly lead to ineffective and inefficient management. Drawing attention to some of the key challenges, and suggesting ways forward, may lead to improved management effectiveness and better conservation outcomes. We highlight six key areas where improvements are needed: 1) stakeholder engagement and communication; 2) fostering strong leadership and the development of achievable long-term goals; 3) knowledge of target species' biology and threats, particularly focusing on filling knowledge gaps that impede management, while noting that in many cases there will be a need for conservation management to proceed initially despite knowledge gaps; 4) setting objectives with measurable outcomes; 5) strategic monitoring to evaluate management effectiveness; and 6) greater accountability for species declines and failure to recover species to ensure timely action and guard against complacency. We demonstrate the importance of these six key areas by providing examples of innovative approaches leading to successful species management. We also discuss overarching factors outside the realm of management influence that can help or impede conservation success. Clear recognition of factors that make species' management more straightforward - or more challenging - is important for setting realistic management objectives, outlining strategic action, and prioritising resources. We also highlight the need to more clearly demonstrate the benefit of current investment, and communicate that the risk of under-investment is species extinctions. Together, improvements in conservation practice, along with increased resource allocation and re-evaluation of the prioritisation of competing interests that threaten species, will help enhance conservation outcomes for threatened species.

\section{Key words}

Adaptive management, conservation, endangered species management, invasive species

\section{Introduction}

Threatened species management, based on assessments of species extinction risk, threat 
management actions, is central to curbing biodiversity loss (Primack, 2006). Despite substantial efforts, notable success has been achieved for relatively few species, and as a result, few threatened species have recovered sufficiently following management interventions to allow delisting (Bottrill et al., 2011; Male and Bean, 2005). In part, this failure can be attributed to a severe lack of resources (Evans et al., 2016; McCarthy et al., 2012). For example in Australia, McCarthy et al. (2008) found that funding for threatened birds was inadequate to prevent further extinctions and facilitate recovery for most listed species, but also that a relatively small increase in resourcing could substantially improve the conservation status of many species. Australian environmental spending is disproportionately low, with Australia one of only several developed countries featuring in the top 40 underfunded countries for conservation spending (Waldron et al., 2013). Further, there has been a sharp reduction in funding over the past decade, with less than five cents for every \$100 of government spending in 2018 directed to biodiversity conservation (ACF, 2018). However, there are several other prominent reasons for the worsening conservation status of many threatened species, such as a failure to address major threats (Johnson et al., 2017), poor enforcement of existing legal protections (Harrison et al., 2016), increasing ignorance of scientific evidence (Sutherland and Wordley, 2017), and a culture of apathy (Russell-Smith et al., 2015). In combination, these issues contribute to inaction or inefficient last minute attempts to rescue species on the brink of extinction (Woinarski et al., 2017).

While part of the blame for ongoing species declines can be attributed to funding shortfalls or socio-political issues, in practice, species declines could also be halted by improving the effectiveness of on-ground conservation effort (Sunderland et al., 2009; Toomey et al., 2017). Although there are examples of successful recovery efforts (see Garnett et al., 2018), many other projects are marred by ad hoc and inefficient planning and implementation (Ferraro and Pattanayak, 2006; Pullin et al., 2004; Sutherland et al., 2004). Further, the effectiveness of conservation management is often poorly evaluated, making it difficult to assess how effective each action was, or what species trajectories would have been in the absence of management intervention (Cresswell and Murphy, 2016). A range of decision frameworks and tools have emerged from conservation planning research to address these challenges (see review by Schwartz et al. (2018)), and there have been substantial advances in the practice of expert elicitation (Hemming et al., 2018). While the increasing use of decision frameworks and support tools over the past 20 years has contributed to enhanced outcomes, there is still substantial room for improvement (Cook et al., 2010; Ferraro and Pattanayak, 2006). 
Here we address challenges that can impede conservation management of threatened species in Australia. We have taken an Australian perspective for several key reasons. These include the fact that Australia supports a highly diverse and endemic range of species and ecosystems, some of which have been recently lost (e.g. 35\% of modern global mammal extinctions have occurred in Australia (Woinarski et al., 2015)), and many more that are threatened (see: Australian Government, 2018). Australia also has a large and diverse array of species recovery programs, with some failures but also prominent successes, upon which to learn from and improve (Garnett et al., 2018). Finally, there is a strong tradition of research excellence in conservation and environmental management in Australia, thus there is scope and capacity within the nation to improve conservation management standards (Harrison, 2006).

We focus on what can be done to improve threatened species management under current constraints. We acknowledge the need for societal changes in human values and their interaction with the environment (Abson et al., 2017), along with a substantial funding increase (Johnson et al., 2017; Waldron et al., 2013). We also address other over-arching factors outside the realm of management control that can impede conservation success. We consider that despite there being a range of program management frameworks readily available, a large implementation gap remains. We provide illustrative case studies of innovative approaches leading to successful species management, noting that 'success' is context-specific and that long-term success will often require continuation of current management trajectories. The views outlined below are the result of a three day workshop of conservation practitioners and researchers with long-term experience in threatened species management, where we worked to collectively identify pitfalls that can lead to ineffective and inefficient management. By drawing attention to some of the key challenges, and providing ways forward, we hope to present a perspective that leads to improved conservation effectiveness and better conservation outcomes.

\section{Challenges and solutions in threatened species management}

Once a decision to manage a threatened species has been made, the management process consists of three broad stages; 1) conceptualisation and planning, 2) management implementation and evaluation, and 3) program evaluation and revision (Fig. 1). These broad categories reflect a standard management cycle (e.g. Schwartz et al., 2018). Below, we identify common challenges that occur across each of these stages and provide examples of 
how they have been overcome. In addition, we discuss challenges in two overarching elements that profoundly impact management; stakeholder engagement and communication, and leadership and personnel. Our evaluation is not exhaustive, but rather reflects personal experience with issues that most commonly arise in the context of threatened species management in Australia. We refer the reader to Schwartz et al. (2018) for guidance on decisions support tools and frameworks for conservation management. We provide a range of species-specific case-studies of successful management programs overcoming many of the challenges discussed in the following section (see Supporting Material Table S1 for additional examples).

\subsection{Conceptualisation and planning}

A key set of interrelated deficiencies in threatened species management can stem from management that is based on inadequate understanding of the target species' ecology or threats (Fig. 1). These deficiencies result in poor problem definition, and a lack of clear and realistic objectives. Although the need for robust understanding of the target species' ecology and threat impacts is well established (Caughley and Gunn, 1996), in reality it is poorly adhered to, and often under-valued. Attaining sufficient ecological knowledge generally requires detailed field work to ascertain, among other things, the target species' distribution, habitat requirements, life history parameters, population trajectories, and threat impacts (Table S1; example 1). These processes need to be understood across the target species' entire distribution (to make informed choices of where to prioritise management), or the proportion of the species' distribution where management efforts will be implemented. Because threat impacts and threat tolerance are shaped by environmental and biotic processes that vary across environmental space (Scheele et al., 2017a), information obtained for one population is not always transferable to other populations. It is also crucial to understand interactions between multiple threats and the capacity for changes in one element of a system to amplify the impacts of other threats. Many present day management practices remain focused on a single threat despite growing scientific understanding of the importance of considering threat interactions (Scheele et al., 2017a).

While there is a clear need for more ecological research, constrained budgets mean that research must be strategic, with a focus on resolving uncertainty that will improve management decisions. The development of a conceptual model of the target system can help identify knowledge gaps and where to focus research. For example, Bode et al. (2017) used 
expert opinion to develop an ecosystem model linking malleefowl (Leipoa ocellata) persistence with abiotic and biotic processes in mallee ecosystems. The model helped managers identify direct and indirect threats facing the species, the likely response of populations when each threat interaction is managed, and the most uncertain threat interactions that require further research.

While inadequate knowledge of a target species' ecology and threat impacts can hamper decisions about management alternatives, in many cases there is a need for conservation management to proceed - or at least be initiated - despite knowledge gaps. In such cases, management is commonly guided by expert judgement. For example, expert judgment informed a decision to undertake aerial phosphite application in 1997 to control Phytophthora cinnamomi in key areas in south west Western Australia, despite uncertainty about phytotoxicity. Urgent management was deemed necessary because the rapid spread of $P$. cinnamomi was driving the local extinction of at least 11 threatened plant species. Importantly, the early, incisive intervention that was based on expert judgement was complimented with monitoring and evaluation of management effectiveness. Monitoring revealed that populations of most species have stabilised following phosphite application (Barrett and Yates, 2015), and that phytotoxic effects are minimal in these vegetation systems (Rathbone and Barrett, 2018).

Challenges arising from ecological uncertainty are often compounded by diverse stakeholder interests, trade-offs, resource limitations and ambiguity surrounding management efficacy. One constructive approach to these complexities is to use formal structured decision making, particularly in cases where there is substantial ecological uncertainty and a need for rapid action (Gregory et al., 2012) (Table S1; example 2). Structured decision making provides a framework to evaluate different alternatives in a transparent way to identify optimal solutions and clearly articulated objectives and actions (Gregory et al., 2012; Runge, 2011; Schwartz et al., 2018). In the absence of a formal decision-making process, ad hoc approaches may be prone to bias, fail to clearly specify objectives and consider all alternatives, or how planned actions will achieve stated objectives.

Under a structured decision making approach, it is critical during the planning stage to differentiate between fundamental objectives (for example, reducing extinction risk for a target species) and means objectives (such as increasing breeding success for a target species by $20 \%$ ) (Gregory et al., 2012). Development of fundamental objectives requires engagement 
of all relevant stakeholders (see examples 3-5 in Table S1 for case studies where a range of stakeholders were engaged in developing fundamental objectives and evaluating management options). It is important that means objectives are linked with performance measures throughout the life of a program to help evaluate efficacy and allow for ongoing refinement (Tear et al., 2005). Canessa et al. (2016) provide a good example of objective setting in the context of ex-situ conservation. They elicited 32 alternative management strategies from experts on the threatened spotted tree frog (Litoria spenceri) and found the strategy that maximised the chance of a wild population persisting for 20 years at the lowest cost. However, they also explored how the optimal strategy depended on the weighting given to the two objectives (i.e. maximise persistence vs minimise cost). In this case, the optimal strategy was sensitive to which objective was considered more important, highlighting the need to explicitly define the fundamental objective early in a management program.

In addition to planning for chosen management actions, contingency planning is a crucial, yet often-neglected, element of threatened species management. Good risk management and planning for unexpected outcomes is not always incorporated into conservation programs (Lindenmayer et al., 2018). Contingency planning requires clear recognition that failure is a possibility - something that managers, practitioners and researchers are not always willing, or able to admit. For example, red fox (Vulpes vulpes) control was initially highly successful for facilitating the recovery of an assemblage of small to medium-sized mammals in southwestern Australia, but after an initial increase in abundance, many species experienced major declines. The declines were thought to be associated with increases in feral cat (Felis catus) predation (Marlow et al., 2015), following meso-predator release of cats as a consequence of fox control (Wayne et al., 2017). This case highlights two key lessons. First, high quality monitoring was crucial to identifying secondary declines, and second, the need for management to plan for the unexpected.

\subsection{Management implementation and evaluation}

In many cases, scientific research needs to be better integrated into management, particularly when there is substantial ecological uncertainty about threat impacts or management effectiveness (Fig. 1). Importantly, research needs to be targeted toward resolving knowledge gaps that will improve management decisions (e.g. Stojanovic et al., 2018). Adaptive management - a more complex extension of structured decision making - provides a 
and 7). Under an adaptive management approach, uncertainty is identified and then alternative management actions are specifically designed to aid learning by resolving uncertainty, while simultaneously progressing management objectives (Runge, 2011; Westgate et al., 2013).

Despite its intuitive appeal, there are few robust examples of active adaptive management of threatened species (Westgate et al., 2013) (an exception is the recently commenced malleefowl program Table S1; example 6). However, less stringent adaptive management is often appropriate and is more commonly applied. An example is a landscape-scale fire management experiment designed to inform and facilitate the recovery of the threatened Gouldian finch (Erythrura gouldiae) in Australia's tropical savanna (Legge et al., 2015). First, research established a negative associated between frequent and intense fire and finch body condition indices. Second, this information was used to develop and then implement a new fire management plan, to which Gouldian finches responded positively. More broadly, barriers to successful adaptive management are well-documented in the literature, with poor communication and a lack of collaborative relationships between managers and researchers commonly cited as a key barrier that needs to be overcome to facilitate management-research integration (Burbidge et al., 2011). Ensuring conservation agencies have research capacity with expertise to expedite management-research relations internally, and to communicate and collaborate with researchers in other institutions, will go some way to addressing this issue.

Once management actions have been implemented, it is essential to conduct reliable monitoring of population responses within a management framework that requires follow up actions as the monitoring progresses (Table S1; examples 8-10). However, a recent review of threatened species monitoring in Australia found that across taxonomic groups, between 21$46 \%$ of threatened vertebrate species received no monitoring at all (Legge et al., 2018). Further, where monitoring does occur, it is often poorly designed, typically having low power to detect changes in population abundance, or to quantify the efficacy of management actions (Legge et al., 2018). Poor quality monitoring reflects under-resourcing, but also monitoring is frequently inhibited by poor data management practices, with data 'stock-piled' over time without analysis, and meta-data and data frequently lost - an issue that is amplified with personnel changes (Lindenmayer and Likens, 2018). Data loss then exacerbates further problems, such as the absence of baselines from which to measure changes and evaluate management success. Finally, and perhaps most troubling, are cases where species are monitored robustly, but the monitoring program lacks triggers for management interventions, 
resulting in species being monitored to extinction, like the Christmas Island pipistrelle (Pipistrellus murrayi) (Lindenmayer et al., 2013). Such failures highlight of the need to link monitoring and management closely, and initiating management without delay.

\subsection{Program evaluation and revision}

Thorough, large-scale evaluations of threatened species conservation efforts in Australia are lacking, a point raised repeatedly within State of the Environment reports (Cresswell and Murphy, 2016) (for a species-specific example of program evaluation see Table S1; example 11). Reporting on resource investment commonly focuses on where and how money was spent, with little quantification of whether management benefited the target species or met objectives (Fig. 1). For example, measures like kilometres of fencing built, or changes in feral predator bait take, are often reported. However, to properly evaluate whether management has had the desired effects, we need to be able to measure whether actions like fencing or predator baiting were associated with increased abundance of the target species of conservation concern (i.e. the fundamental objective) (Table S1; examples 12 and 13). Inadequate evaluation is related to poorly formulated objectives that lack specific, measurable outcomes. As a first step, we suggest that assessment of management effectiveness is incorporated into funding programs, and mandated as a condition of funding being granted (requiring improved monitoring). However, there may be little political appetite for changes requiring greater accountability of spending if funding bodies are currently rewarded with easily met targets that can be used to demonstrate so-called conservation success. In addition, the fundamental mismatch between biological and political funding timeframes remains an ongoing challenge.

At a broader level, evaluation efforts are inhibited by lack of accountability for species declines and extinctions, and the absence of independent reviews of conservation programs (for a species-specific example see Table S1; example 14). The current Australian system lacks a direct chain of accountability for species declines or extinctions, with Woinarski et al. (2017) highlighting the need for legislation adjustments to address this shortcoming. Further, under Australian legislation, the implementation of national recovery actions is not mandated, which inhibits efforts to improve accountability and ensure timely actions. In contrast, the U.S. Endangered Species Act, provides clear legislative responsibilities for the U.S. Fish and Wildlife Service to prepare and implement recovery plans, and develop policy and guidelines for recovery plan preparation (Hoekstra et al., 2002). 
284 Periodic independent review can be useful to ensure transparency in decision making and can help guard against complacency, where management slips into a 'business as usual' routine, without evaluation of new evidence or approaches. Given the complexities and uncertainty inherent in many threatened species management programs, there is a need for periodic reevaluation of current practises and the foundational knowledge base (Bottrill et al., 2011; Walsh et al., 2013). Avoiding complacency also requires awareness of the shifting baseline phenomena, whereby gradual deterioration in a species' status or habitats occurs too slowly to be registered by individuals or monitoring programs (Bilney, 2014). For example, plant species with long generation times typical of many Australian threatened woody shrubs and trees may show significant time delays to extinction, well beyond standard monitoring periods (see: Krauss et al., 2010).

\subsection{Stakeholder engagement and communication}

The need to involve a wide range of decision makers and stakeholders in threatened species conservation has long been recognised (Garnett et al., 2018). In the context of threatened species management in Australia, improved engagement and communication is needed on multiple levels; conservation practitioners and managers are often intermediaries between decision makers that control resources, and stakeholders who are involved in implementing management, or who are impacted by management actions (Table S1; example 15). In the first case, there is a need to provide convincing and robust justification to decision makers of the value and merits of investing in threatened species conservation. The justification for threatened species conservation is strongest for programs that engage a wide range of stakeholders to ensure all objectives are considered, provide clearly articulated benefits, and describe measurable objectives that can be used to demonstrate the value of investing resources. In the second case, stakeholders who are impacted by threatened species protection or management need to be integrated into decision-making processes, and should be kept informed of developments throughout the life-cycle of the program. The aim of this dialogue is to develop mutually acceptable actions, although compromise on both sides is often needed (Redpath et al., 2013). These actions will be most effective when conservation practitioners and managers build strong relationships with the community of affected stakeholders, and work to ensure that decision making is transparent (Mishra et al., 2017). Strong relationships are needed to overcome the 'knowing-doing' gap, whereby we know what to do, but communicating what is needed, and then doing it, is a barrier (Hulme, 2014). 
In addition to regular and effective communication with decision makers and stakeholders,

317 communication with the broader community is required to increase understanding of

318 conservation challenges and current management approaches (Table S1; example 16)

319 (Redpath et al., 2013). Ultimately, efforts to increase resource allocation to conservation

320 programs are dependent to a large extent on increasing the value the community places on

321 biodiversity conservation. It is the job of conservation scientists and managers to

322 communicate good news stories of successful programs (Garnett et al., 2018), but also to

323 highlight the major challenges involved, and that the consequence of inaction is species

324 extinction.

\section{$\underline{\text { 2.5. Leadership and personnel }}$}

Delivery of successful species conservation programs requires strong leadership and a wellfunctioning team (Black et al., 2011) (Table S1; example 17). Conversely, poor leadership and dysfunctional teams have been identified as a reason for failure in some conservation programs (Battisti, 2017). A key barrier to the success of threatened species programs is indecisive and overly risk averse leadership. Indecisiveness can result from high levels of uncertainty, poor individual leadership, or in response to broader drivers such as competing priorities, or a lack of political will to act (Meek et al., 2015). In the cases of many threatened species, there is often an urgent need for action, without which there is an imminent risk of extinction (Table S1; example 18). For example, failure to enact threat reduction or establishment of ex-situ populations played a role in the extinction of three Australian vertebrate species between 2009 and 2014 (Woinarski et al., 2017). Conservation success is influenced by myriad factors, many of which are outside the control of conservation practitioners; however, ensuring good leadership and personnel is something that can often be directly shaped by conservation practitioners, and hence something we need to get right

340 (Black et al., 2011).

A commonality we have often observed in successful programs is the important role of a 'species champion'. Species champions come from a diverse range of backgrounds, from someone in government who advocates strongly for a species, to private landowners, and passionate community members. Species champions can often overcome legislative and funding shortfalls to achieve successful outcomes. Key traits include a robust understanding of the target species' ecology and threats, but also strong planning skills and the capacity to build and organise a team - including engaging with experts where needed. Species 
champions are also innovators, developing new approaches to successfully manage species

349 (Clark and Kellert, 1988). Most important, however, is their capacity to be optimistic, including clearly articulate a positive long-term vision for the successful recovery of the target species (i.e. 'stretch goals').

Negative sentiments are common in threatened species management, and it is hard to overstate the value of positive visions for success (Redford et al., 2016). For example, Gillespie et al. (2018) identify that the presence of a species champion was crucial for the long-term success of conservation programs for several critically endangered frog species from south-eastern Australia (Table 1; example 19). Of course, having a program driven by a species champion can create vulnerability if that person becomes no longer involved in the program. As such, there is a need to foster institutional memory through the long-term retention of key players, ensure adequate succession planning, and encourage and facilitate knowledge transfer between multiple players (Holling and Meffe, 1996). While long-term institutional involvement is often key, programs that develop a vision broader than any one institution, are often highly successful (Redford et al., 2016).

\section{What makes threatened species management so difficult?}

364 In the preceding section we outlined common challenges in threatened species management.

365 However, there are also over-arching factors outside the sphere of management influence that can impede conservation success. Clear recognition of factors that make a species' management more straightforward - or more challenging - is important for setting realistic management objectives and prioritising resources. Below we outline some recurring impediments to threatened species management.

\subsection{Threatened species management conflicts with other priorities}

Threatened species management can directly conflict with competing social and economic priorities. This is especially the case when threats to species are primarily human driven, such as habitat loss associated with land-use practices. An example is the conservation of Leadbeater's possum (Gymnobelideus leadbeateri); a critically endangered species that occurs in the wet mountain ash (Eucalyptus regnans) forests of Victoria. Long-term research has identified key threats to the survival of the species; habitat loss and degradation from forestry activities and wildfire (Lindenmayer et al., 2016). In terms of promoting this species' conservation, the science is clear; we need to set aside large areas of forested land for conservation, thereby removing the key threat of logging (Lindenmayer et al., 2016). The 
economic costs of ending logging (including job loss) would be more than offset by economic gains to agriculture, water provisioning, tourism, and carbon storage (Keith et al., 2017). However, this solution remains politically challenging due to the reaction of the forestry industry to such a policy. A similar conflict is also apparent in the Australian Capital Territory where government policy promotes continued urban expansion into grassland and woodland ecosystems that provide critical habitat for several threatened reptiles and invertebrate species (Howland et al., 2016). In both cases, known threats to highly threatened species are perpetuated due to prioritisation of competing interests ahead of those species. Improving conservation outcomes in such cases is highly challenging and will ultimately require decision makers to accept greater responsibility for the fate of threatened species. We suggest that it is crucial to explicitly recognise that current policy choices prioritise economic or social interests that are key threats to species, and clearly acknowledge and communicate that threatened species will be negatively impacted, and at risk of extinction if the status quo is maintained. Subsequently, this may trigger a rethink of societal values and re-analysis of the economic value of competing interests; allowing society to choose whether priorities should be shifted to promote species conservation (Abson et al., 2017). Such rethinking is particularly pertinent in light of evidence showing strong public support for threatened species conservation (McCune et al., 2017).

\subsection{Unknown threats and unknown solutions}

In some cases, species can experience major declines resulting from an unknown threat, or if effective management actions to combat a threat are not known. Enigmatic declines are increasingly common in a globalised world where new threats can rapidly emerge. An illustrative example is the enigmatic declines of hundreds of frog species, both in Australia and globally, from the 1970s onwards. In Australia, the disappearances of several rainforest frog species was first documented in 1979 (Scheele et al., 2017b). Further declines were observed across eastern Australia in the 1980s and 1990s, but it was not until 1998 that a previously unknown disease - chytridiomycosis - was identified and demonstrated to be the cause of frog declines (Scheele et al., 2017b). Following identification of the threat, it took a further decade to develop management actions, and these remain only partially effective (Scheele et al., 2014). In total, it took over three decades from threat emergence and documentation of initial species declines to the development of conservation actions to combat chytridiomycosis. In the intervening years, seven species of frog likely went extinct and a further six species declined severely and are at high risk of extinction without targeted 
413 ex-situ programs (Scheele et al., 2017b). While there is no single, easy method for identifying 414 novel threats and developing effective responses, long-term investment in ecological research 415 and monitoring will build capacity to better unravel emerging causes of decline and develop 416 effective management responses.

\section{$417 \quad 3.3$. Highly mobile and cryptic species}

418 Coordinating and implementing conservation actions across large spatial scales covering 419 multiple land tenures and government jurisdictions is challenging. This is compounded by the 420 fact that information on the ecology, threats and effectiveness of management actions is particularly lacking for nomadic and migratory species (Webb et al., 2017). An example of a species with such management challenges is the regent honeyeater (Anthochaera phrygia). This semi-nomadic species is critically endangered with an estimated population size of only 350-400 adults, distributed across a $600000 \mathrm{~km}^{2}$ range across parts of South Australia, Victoria, New South Wales, Australian Capital Territory and Queensland. This species moves across vast distances in response to flowering of nectar producing trees. Restoration plantings have been identified as a key management action, but deciding where to establish planting is highly problematic due to the species' transient occurrence, and the lag between planting and maturity. Similar challenges are also evident for international migratory species that face severe threats in parts of their range that undermine conservation actions in other regions, and for which managers in Australia have limited capacity to influence (Hansen et al., 2018). In addition, many other traits common to threatened species, such as irruptive population dynamics (arid rodent species), highly cryptic behaviour (pygmy bluetongue, Tiliqua adelaidensis) and extreme rarity (plains wanderer, Pedionomus torquatus; night parrot, Pezoporus occidentalis), can make management challenging (Dickman et al., 2018).

\subsection{Lack of critical reflection on management practices}

For management of threatened species to succeed, it is critical not only that proper evaluation is undertaken to understand which actions work and which fail, but also to reflect on the process by which decisions are taken and how those processes can be systematically improved over time. This is the essence of adaptive management, which provides a powerful framework to undertake threatened species management (Runge, 2011). It is particularly useful in cases where there is uncertainty surrounding the effectiveness of different management approaches, and where actions are implemented repeatedly, providing opportunities for learning to be integrated and management adjusted accordingly (Runge, 
2011). However, the term adaptive management is at risk of becoming a panchreston - a term associated with such a wide range of definitions that it becomes almost meaningless. A lack of clear consensus of what is adaptive management, especially amongst practitioners, is highly problematic (Westgate et al., 2013). The label of 'adaptive management' is applied liberally to cover very simple ad hoc trial and error management programs (with no/limited formal monitoring), right through to complex programs that adhere to the core principles of adaptive management, like conceptual model development, thorough monitoring and program evaluation and refinement. In practice, the best point of this continuum to apply to any conservation problem is context-specific; sometimes ad hoc trial and error is exactly the right approach to take. However, since adaptive management conveys the sense of 'bestpractice', programs so-labelled are sometimes perceived to be immune from scrutiny and without need for improvement. Failure to recognise the need to continually improve management hinders progress on species conservation.

\section{Key lessons from threatened species management in Australia}

Based on several decades of our collective experience addressing a diverse range of management, policy, and research challenges relating to threatened species, we have observed several lessons broadly applicable to threatened species management:

1. We need to learn from failure. This requires a cultural shift from hiding and downplaying failures, to openly acknowledging failure and most importantly, ensuring that we learn from failures to avoid repeating the same mistakes (Redford and Taber, 2000). To enable failures to be reported and evaluated, programs need to realistically evaluate failure risk in the planning stage.

2. In complex situations, there is a need to slow down and take stock of current knowledge, identify uncertainty and develop a structured approach to move forward. Too often, with a perceived urgency for action, complex problems are glossed over, which can later resurface, sometimes to create insurmountable problems (Lindenmayer and Likens, 2018). The development of a conceptual model can help identify key areas of uncertainty. At the same time, it is crucial to ensure that management does not stall due to uncertainty. information of threatened species trajectories. This can be achieved through long-term population abundance or occurrence monitoring, or detailed evaluation of target species' 
demography, with subsequent projections of population abundance. Without improved monitoring of management efficacy and species' population trajectories, progress on refining and improving management actions will be unacceptably slow.

4. The formation of successful species recovery teams requires a diversity of people with complementary skillsets (Clark and Westrum, 1989), and bringing in people with different skills during each stage of the program. For example, specialist facilitators with experience in structured decision making can help with the problem definition stage of planning, while statisticians might play a role designing monitoring so that it has sufficient power to detect management effectiveness. Threatened species recovery is a multifaceted process, and unbalanced teams may fail to deliver successful conservation outcomes.

5. When recovery plans are deemed necessary, it is crucial that they are funded and implemented, with clear accountability for actions outlined and enforced, and thorough evaluation of management effectiveness. Evaluations of recovery plans and associated data should be complied in a central depository for public access.

\section{Conclusion}

491 Threatened species conservation is a cornerstone of efforts to curb global biodiversity loss. A universal challenge in threatened species management remains limited resources (Johnson et al., 2017). Efforts to increase funding require managers and scientists to clearly demonstrate the benefit of current investment, and better communicate that the risk of under-investment is species extinctions. In parallel, there is opportunity for improvement in management practices. We highlight the importance of: 1) inclusive stakeholder engagement and communication; 2) fostering strong leadership and the development of ambitious long-term goals; 3) knowledge of target species' ecology and threats, particularly focusing on filling knowledge gaps that impede development of effective management; 4) setting objectives with measurable outcomes; 5) strategic monitoring and action evaluation; and 6) greater accountability for species declines to ensure timely action and guard against complacency.

502 Together, good conservation practice, along with increased resource allocation and reevaluation of the prioritisation of competing interests that threaten species, will help ensure enhanced conservation outcomes for threatened species.

\section{Acknowledgements}


506 Funding from the Australian Government's National Environmental Science Programme

507 through the Threatened Species Recovery Hub facilitated the workshop and preparation of

508 this article. David Coates contributed substantially to the development of the arguments

509 presented in this article.

510

511 Appendix A: Supporting Material Table S1. Case-studies of threatened species management 512 in Australia demonstrating key principles described in the main text. 


\section{References}

515 Abson, D.J., Fischer, J., Leventon, J., Newig, J., Schomerus, T., Vilsmaier, U., von Wehrden,

516 H., Abernethy, P., Ives, C.D., Jager, N.W., 2017. Leverage points for sustainability

517 transformation. Ambio 46, 30-39.

518 ACF, 2018. Australian Conservation Foundation. Background brief: Environment spending

519 in Australia. https://www.acf.org.au/background briefs accessed 10-5-2018. .

520 Australian Government, 2018. Australian Government. Species Profile and Threats Database:

521 EPBC Act List of Threatened Fauna. http://www.environment.gov.au/cgi-

522 bin/sprat/public/publicthreatenedlist.pl accessed 10-5-2018. .

523 Barrett, S., Yates, C.J., 2015. Risks to a mountain summit ecosystem with endemic biota in

524 southwestern Australia. Austral Ecol. 40, 423-432.

525 Battisti, C., 2017. How to make (in) effective conservation projects: look at the internal

526 context! Anim. Conserv. 20, 305-307.

527 Bilney, R.J., 2014. Poor historical data drive conservation complacency: The case of mammal

528 decline in south-eastern Australian forests. Austral Ecol. 39, 875-886.

529 Black, S.A., Groombridge, J.J., Jones, C.G., 2011. Leadership and conservation

530 effectiveness: finding a better way to lead. Conserv. Lett. 4, 329-339.

531 Bode, M., Baker, C.M., Benshemesh, J., Burnard, T., Rumpff, L., Hauser, C.E., Lahoz-

532 Monfort, J.J., Wintle, B.A., 2017. Revealing beliefs: using ensemble ecosystem modelling to

533 extrapolate expert beliefs to novel ecological scenarios. Methods Ecol Evol 8, 1012-1021.

534 Bottrill, M.C., Walsh, J.C., Watson, J.E., Joseph, L.N., Ortega-Argueta, A., Possingham,

535 H.P., 2011. Does recovery planning improve the status of threatened species? Biol. Conserv.

$536144,1595-1601$.

537 Burbidge, A.H., Maron, M., Clarke, M.F., Baker, J., Oliver, D.L., Ford, G., 2011. Linking

538 science and practice in ecological research and management: How can we do it better? Ecol.

539 Manage. Restor. 12, 54-60.

540 Canessa, S., Converse, S.J., West, M., Clemann, N., Gillespie, G., McFadden, M., Silla, A.J.,

541 Parris, K.M., McCarthy, M.A., 2016. Planning for ex situ conservation in the face of

542 uncertainty. Conserv. Biol. 30, 599-609.

543 Caughley, G., Gunn, A., 1996. Conservation biology in theory and practice. Blackwell

544 Science, Cambridge, U.S.

545 Clark, T.W., Kellert, S.R., 1988. Toward a policy paradigm of the wildlife sciences.

546 Renewable Resources Journal 6, 7-16. 
Clark, T.W., Westrum, R., 1989. High-performance teams in wildlife conservation: A species reintroduction and recovery example. Environmental Management 13, 663-670. Cook, C.N., Hockings, M., Carter, R., 2010. Conservation in the dark? The information used to support management decisions. Front. Ecol. Environ. 8, 181-186.

Cresswell, I., Murphy, H., 2016. Biodiversity. In: Australia state of the environment 2016, Australian Government Department of the Environment and Energy, Canberra, https://soe.environment.gov.au/theme/biodiversity, DOI 10.4226/94/58b65ac828812. Dickman, C.R., Greenville, A.C., Wardle, G.M., 2018. Determining trends in irruptive desert species, in: Legge, S., Lindenmayer, D.B., Robinson, N.M., Scheele, B.C., Southwell, D.M., Wintle, B.A. (Eds.), Monitoring threatened species and ecological communities. CSIRO Publishing, Melbourne.

Evans, D.M., Che-Castaldo, J.P., Crouse, D., Davis, F.W., Epanchin-Niell, R., Flather, C.H., Frohlich, R.K., Goble, D.D., Li, Y.W., Male, T.D., 2016. Species recovery in the United States: Increasing the effectiveness of the Endangered Species Act. Issues in Ecology, Report Number 20. Ecological Society of America. 27 p. Ferraro, P.J., Pattanayak, S.K., 2006. Money for nothing? A call for empirical evaluation of biodiversity conservation investments. PLoS Biol. 4, e105. threatened species: a book of hope. CSIRO Publishing, Melbourne. Gillespie, G.R., Hunter, D.A., Hollis, G., Scheele, B.C., West, M., 2018. A tale of threatened frogs: demonstrating the value of long-term monitoring, in: Legge, S., Lindenmayer, D.B., Robinson, N.M., Scheele, B.C., Southwell, D.M., Wintle, B.A. (Eds.), Monitoring threatened species and ecological communities. CSIRO Publishing, Melbourne. decision making: a practical guide to environmental management choices. John Wiley \& Sons.

Hansen, B.D., Clemens, R.S., Gallo-Cajiao, E., Jackson, M.V., Kingsford, R.T., Maguire, G.S., Maurer, G., Milton, D.A., Rogers, D.I., Weller, D.R., Weston, M.A., Woehler, E.J., Fuller, R.A., 2018. Shorebird monitoring in Australia: a successful long-term collaboration among citizen scientists, governments and researchers, in: Legge, S., Lindenmayer, D.B., Robinson, N.M., Scheele, B.C., Southwell, D.M., Wintle, B.A. (Eds.), Monitoring threatened species and ecological communities. CSIRO Publishing, Melbourne. Harrison, A.L., 2006. Who's who in conservation biology — an authorship analysis. Conserv. Biol. 20, 652-657. 
Harrison, J.R., Roberts, D.L., Hernandez-Castro, J., 2016. Assessing the extent and nature of wildlife trade on the dark web. Conserv. Biol. 30, 900-904. Hemming, V., Burgman, M., Hanea, A., McBride, M., Wintle, B., 2018. Structured expert elicitation using the IDEA protocol. Methods Ecol Evol 9, 169-180. Hoekstra, J.M., Clark, J.A., Fagan, W.F., Boersma, P.D., 2002. A comprehensive review of Endangered Species Act recovery plans. Ecol. Appl. 12, 630-640. Holling, C.S., Meffe, G.K., 1996. Command and control and the pathology of natural resource management. Conserv. Biol. 10, 328-337.

Howland, B.W., Stojanovic, D., Gordon, I.J., Fletcher, D., Snape, M., Stirnemann, I.A., Lindenmayer, D.B., 2016. Habitat preference of the striped legless lizard: Implications of grazing by native herbivores and livestock for conservation of grassland biota. Austral Ecol. 41, 455-464. Hulme, P.E., 2014. Bridging the knowing-doing gap: know-who, know-what, know-why, know-how and know-when. J. Appl. Ecol. 51, 1131-1136. Johnson, C.N., Balmford, A., Brook, B.W., Buettel, J.C., Galetti, M., Guangchun, L., Wilmshurst, J.M., 2017. Biodiversity losses and conservation responses in the Anthropocene. Science 356, 270-275.

Keith, H., Vardon, M., Stein, J.A., Stein, J.L., Lindenmayer, D., 2017. Ecosystem accounts define explicit and spatial trade-offs for managing natural resources. Nature Ecology \& Evolution 1, 1683-1692.

601 Krauss, J., Bommarco, R., Guardiola, M., Heikkinen, R.K., Helm, A., Kuussaari, M., 602 Lindborg, R., Öckinger, E., Pärtel, M., Pino, J., 2010. Habitat fragmentation causes immediate and time-delayed biodiversity loss at different trophic levels. Ecol. Lett. 13, 597605.

Legge, S., Garnett, S., Maute, K., Heathcote, J., Murphy, S., Woinarski, J.C., Astheimer, L., 2015. A landscape-scale, applied fire management experiment promotes recovery of a population of the threatened Gouldian finch, Erythrura gouldiae, in Australia's tropical savannas. PloS One 10, e0137997. Legge, S., Lindenmayer, D.B., Robinson, N.M., Scheele, B.C., Southwell, D.M., Wintle, B.A., 2018. Monitoring threatened species and ecological communities. CSIRO Publishing,

\section{Melbourne.}

612 Lindenmayer, D.B., Blair, D., McBurney, L., Banks, S.C., 2016. Ignoring the science in

613 failing to conserve a faunal icon-major political, policy and management problems in 614 preventing the extinction of Leadbeater's possum. Pac. Conserv. Biol. 21, 257-265. 
616 Publishing, Melbourne.

617 Lindenmayer, D.B., Piggott, M.P., Wintle, B.A., 2013. Counting the books while the library 618 burns: why conservation monitoring programs need a plan for action. Front. Ecol. Environ.

$61911,549-555$.

620 Lindenmayer, D.B., Wood, J., MacGregor, C., Foster, C., Scheele, B., Tulloch, A., Barton, 621 P., Banks, S., Robinson, N., Dexter, N., 2018. Conservation conundrums and the challenges 622 of managing unexplained declines of multiple species. Biol. Conserv. 221, 279-292.

623 Male, T.D., Bean, M.J., 2005. Measuring progress in US endangered species conservation.

624 Ecol. Lett. 8, 986-992.

625 Marlow, N.J., Thomas, N.D., Williams, A.A., Macmahon, B., Lawson, J., Hitchen, Y., 626 Angus, J., Berry, O., 2015. Cats (Felis catus) are more abundant and are the dominant 627 predator of woylies (Bettongia penicillata) after sustained fox (Vulpes vulpes) control. Aust.

628 J. Zool. 63, 18-27.

629 McCarthy, D.P., Donald, P.F., Scharlemann, J.P., Buchanan, G.M., Balmford, A., Green, 630 J.M., Bennun, L.A., Burgess, N.D., Fishpool, L.D., Garnett, S.T., 2012. Financial costs of 631 meeting global biodiversity conservation targets: current spending and unmet needs. Science $632338,946-949$.

633 McCarthy, M.A., Thompson, C.J., Garnett, S.T., 2008. Optimal investment in conservation of 634 species. J. Appl. Ecol. 45, 1428-1435.

635 McCune, J., Carlsson, A.M., Colla, S., Davy, C., Favaro, B., Ford, A.T., Fraser, K.C., 636 Martins, E.G., 2017. Assessing public commitment to endangered species protection: A 637 Canadian case study. FACETS 2, 178-194.

638 Meek, M.H., Wells, C., Tomalty, K.M., Ashander, J., Cole, E.M., Gille, D.A., Putman, B.J., 639 Rose, J.P., Savoca, M.S., Yamane, L., 2015. Fear of failure in conservation: the problem and 640 potential solutions to aid conservation of extremely small populations. Biol. Conserv. 184, $641 \quad 209-217$.

642 Mishra, C., Young, J.C., Fiechter, M., Rutherford, B., Redpath, S.M., 2017. Building 643 partnerships with communities for biodiversity conservation: lessons from Asian mountains. 644 J. Appl. Ecol. 54, 1583-1591.

645 Primack, R.B., 2006. Essentials of conservation biology. Sunderland, Mass: Sinauer 646 Associates.

647 Pullin, A.S., Knight, T.M., Stone, D.A., Charman, K., 2004. Do conservation managers use 648 scientific evidence to support their decision-making? Biol. Conserv. 119, 245-252. 
649 Rathbone, D., Barrett, S., 2018. Long-term phosphite application maintains species

650 assemblages, richness and structure of plant communities invaded by Phytophthora

651 cinnamomi. Austral Ecol. https://doi.org/10.1111/aec.12574.

652 Redford, K.H., Aune, K., Plumb, G., 2016. Hope is a bison. Conserv. Biol. 30, 689-691.

653 Redford, K.H., Taber, A., 2000. Writing the wrongs: developing a safe-fail culture in

654 conservation. Conserv. Biol. 14, 1567-1568.

655 Redpath, S.M., Young, J., Evely, A., Adams, W.M., Sutherland, W.J., Whitehouse, A., Amar, 656 A., Lambert, R.A., Linnell, J.D., Watt, A., 2013. Understanding and managing conservation conflicts. Trends Ecol. Evol. 28, 100-109.

Runge, M.C., 2011. An introduction to adaptive management for threatened and endangered species. Journal of Fish and Wildlife Management 2, 220-233. Russell-Smith, J., Lindenmayer, D., Kubiszewski, I., Green, P., Costanza, R., Campbell, A., 2015. Moving beyond evidence-free environmental policy. Front. Ecol. Environ. 13, 441448.

Scheele, B.C., Foster, C.N., Banks, S.C., Lindenmayer, D.B., 2017a. Niche contractions in declining species: mechanisms and consequences. Trends Ecol. Evol. 32, 346-355. Scheele, B.C., Hunter, D.A., Grogan, L., Berger, L., Kolby, J., McFadden, M., Marantelli, G., Skerratt, L.F., Driscoll, D.A., 2014. Interventions for reducing extinction risk in chytridiomycosis-threatened amphibians. Conserv. Biol. 28, 1195-1205. Scheele, B.C., Skerratt, L.F., Grogan, L.F., Hunter, D.A., Clemann, N., McFadden, M., Newell, D., Hoskin, C.J., Gillespie, G.R., Heard, G.W., 2017b. After the epidemic: Ongoing declines, stabilizations and recoveries in amphibians afflicted by chytridiomycosis. Biol. Conserv. 206, 37-46.

Schwartz, M.W., Cook, C.N., Pressey, R.L., Pullin, A.S., Runge, M.C., Salafsky, N., Sutherland, W.J., Williamson, M.A., 2018. Decision support frameworks and tools for conservation. Conserv. Lett. 11, 1-12. Stojanovic, D., Alves, F., Cook, H., Crates, R., Heinsohn, R., Peters, A., Rayner, L., Troy, S.N., Webb, M.H., 2018. Further knowledge and urgent action required to save orangebellied parrots from extinction. Emu-Austral Ornithology 118, 126-134. Sunderland, T., Sunderland-Groves, J., Shanley, P., Campbell, B., 2009. Bridging the gap: how can information access and exchange between conservation biologists and field practitioners be improved for better conservation outcomes? Biotropica 41, 549-554. based conservation. Trends Ecol. Evol. 19, 305-308. 
683 Sutherland, W.J., Wordley, C.F., 2017. Evidence complacency hampers conservation. Nature 684 Ecology \& Evolution 1, 1215.

685 Tear, T.H., Kareiva, P., Angermeier, P.L., Comer, P., Czech, B., Kautz, R., Landon, L., 686 Mehlman, D., Murphy, K., Ruckelshaus, M., 2005. How much is enough? The recurrent 687 problem of setting measurable objectives in conservation. AIBS Bulletin 55, 835-849.

688 Toomey, A.H., Knight, A.T., Barlow, J., 2017. Navigating the space between research and 689 implementation in conservation. Conserv. Lett. 10, 619-625.

690 Waldron, A., Mooers, A.O., Miller, D.C., Nibbelink, N., Redding, D., Kuhn, T.S., Roberts, 691 J.T., Gittleman, J.L., 2013. Targeting global conservation funding to limit immediate 692 biodiversity declines. Proc. Natl. Acad. Sci. USA 110, 12144-12148.

693 Walsh, J.C., Watson, J.E., Bottrill, M.C., Joseph, L.N., Possingham, H.P., 2013. Trends and 694 biases in the listing and recovery planning for threatened species: an Australian case study. 695 Oryx 47, 134-143.

696 Wayne, A.F., Maxwell, M.A., Ward, C.G., Wayne, J.C., Vellios, C.V., Wilson, I.J., 2017.

697 Recoveries and cascading declines of native mammals associated with control of an 698 introduced predator. J. Mammal. 98, 489-501.

699 Webb, M.H., Terauds, A., Tulloch, A., Bell, P., Stojanovic, D., Heinsohn, R., 2017. The 700 importance of incorporating functional habitats into conservation planning for highly mobile 701 species in dynamic systems. Conserv. Biol. 31, 1018-1028.

702 Westgate, M.J., Likens, G.E., Lindenmayer, D.B., 2013. Adaptive management of biological 703 systems: a review. Biol. Conserv. 158, 128-139.

704 Woinarski, J.C., Burbidge, A.A., Harrison, P.L., 2015. Ongoing unraveling of a continental 705 fauna: Decline and extinction of Australian mammals since European settlement. Proc. Natl. 706 Acad. Sci. USA 112, 4531-4540.

707 Woinarski, J.C., Garnett, S.T., Legge, S.M., Lindenmayer, D.B., 2017. The contribution of 708 policy, law, management, research, and advocacy failings to the recent extinctions of three 709 Australian vertebrate species. Conserv. Biol. 31, 13-23. 


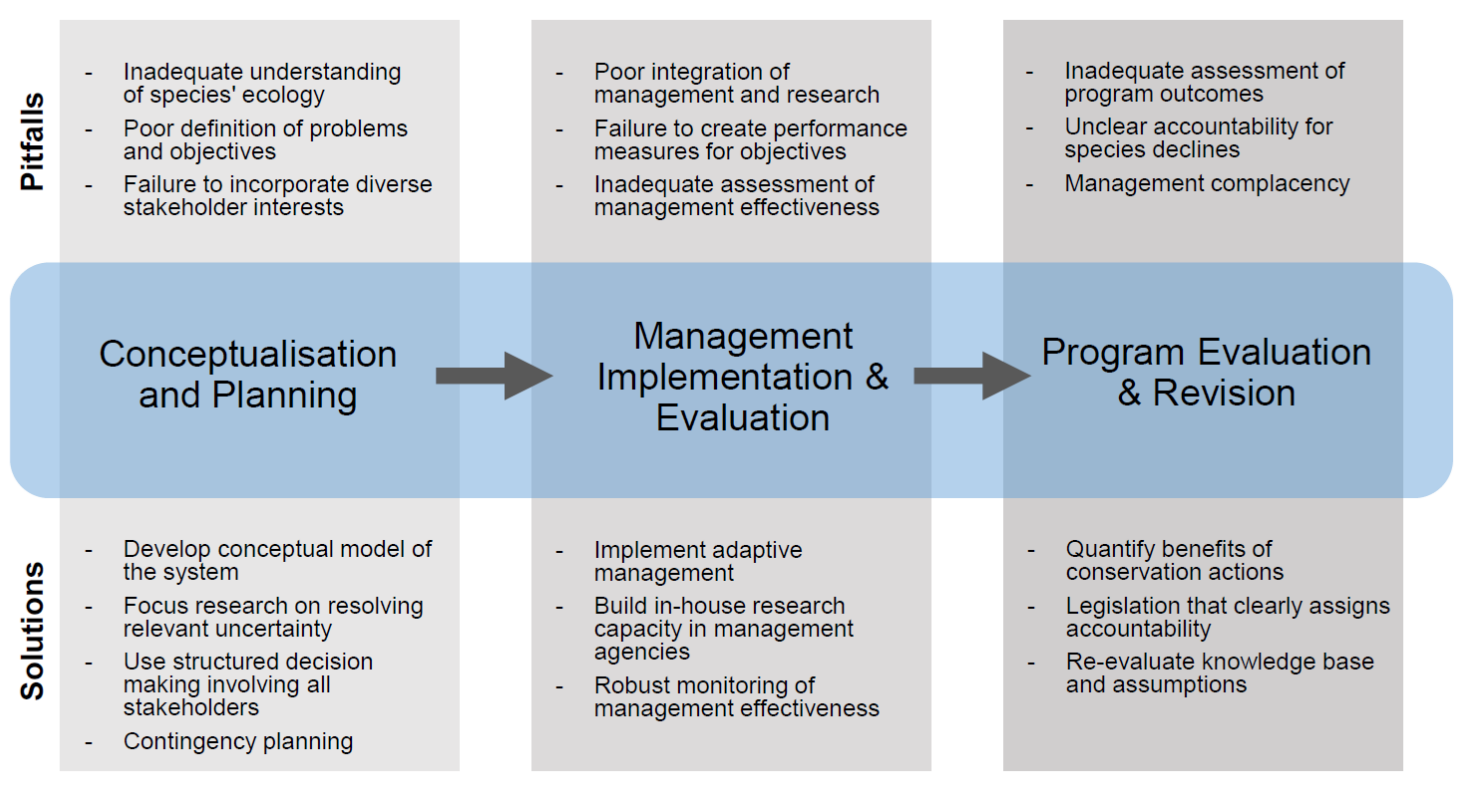

712

713 Figure 1. Common pitfalls and potential solutions for improving threatened species

714 management. 


\section{Appendix A. Supporting Material}

718 Title: How to improve threatened species management: an Australian perspective

719

720

Authors: Scheele, B.C., Legge, S., Armstrong, D.P., Copley, P., Robinson, N., Southwell, D.,

Westgate, M.J. \& Lindenmayer, D.B.

722

Table S1. Case-studies of threatened species management in Australia demonstrating key principles described in the main text. For each species, the Environment Protection and Biodiversity

725 Conservation Act 1999 species status is provided. 


\section{Conceptualisation and planning}

Example 1: Importance of thorough ecological knowledge for managing inter-dependencies between threatened species

The conservation of a threatened species may be dependent on the management and conservation of another threatened species. For example, the recently listed, critically endangered plant-louse (Trioza barrettae) is entirely dependent on a single host plant species, the critically endangered Banksia brownie, which is under severe threat from the emerging pathogen Phytophthora cinnamomi. Addressing rapid decline and coextinction of both species has involved translocations of $B$. brownii to Phytophthora free areas, followed by translocations of the plant-louse onto the translocated host (Moir et al., 2016). Consideration of all aspects of a species biology, including dependants, is crucial for effective threatened species management.

Example 2: Using structured decision making to target research and learning

Deciding on a course of action for threatened species is difficult when the fundamental objective and effect of management alternatives is uncertain. Bode et al. (2017) ran a series of structured decision-making workshops with experts in malleefowl (Leipoa ocellata, listed as vulnerable) ecology and mallee ecosystems to identify management alternatives for malleefowl, as well as the fundamental objective of a management program. Experts helped develop an ecosystem model for the species that quantified the uncertainty of proposed management actions. This identified knowledge gaps, the need for further learning, and formed the basis an adaptive management project.

\section{Example 3: Identifying fundamental objectives and optimal management actions}

Clear specification of the fundamental objective is crucial to successful management because it determines the choice of management action. Canessa et al (2016) developed a framework to determine whether to adopt ex-situ management for threatened species. They applied their framework to the critically endangered spotted tree frog (Litoria spenceri) in Australia and found the management strategy that maximised the chance of a wild population surviving for 20 years at the lowest cost. The optimal strategy depended on the weightings placed on the objectives (maximise persistence or minimise cost) by managers.

\section{Example 4: Integrating threatened plant conservation into fire management}

Managers often have to juggle multiple objectives, and assimilate them into broader management goals. Auld and Scott (2013) provide a case-study where the ecological requirements of the endangered shrub, Grevillea caleyi, were incorporated into broader fire planning protocols. The integrated fire management plan considered associated management actions such as weed control aimed at managing small ridgetop populations adjacent to urban areas, while ensuring threatened species management objectives were addressed.

\section{Example 5: Resolving competing objectives between multiple threatened species}

Threatened species can themselves be a threatening process to other threatened species, potentially creating ethical dilemmas of how to prioritise management. For example, browsing by rabbits (Oryctolagus cuniculus) and the endangered Quokka (Setonix brachyurus) was shown to contribute to the rapid and recent decline in numbers of critically endangered plants; Andersonia axilliflora, Darwinia collina, Latrobea colophona, Leucopogon gnaphalioides. These species are also threatened by Phytophthora cinnamomi and frequent fire. Rathbone and Barrett (2017) demonstrated that potentially conflicting objectives could be managed by installing wire enclosures around threatened plants to eliminate browsing effects.

\section{Management implementation and evaluation}

Example 6: Implementing adaptive management to resolve uncertainty around management effectiveness Adaptive management can help learn which management action is best for a species while simultaneously achieving management objectives. The development of the adaptive management program for the vulnerable malleefowl (Leipoa ocellata) demonstrates that by integrating knowledge from existing databases, and engaging with all stakeholders, greater understanding of complex ecological problems can be realised and solutions developed to address uncertainty (Benshemesh et al., 2018). This process involved developing conceptual models of how threatened species, threatening processes and management interact. Different management actions were considered and their effect on the system was modelled. This led to clear management actions to test in an adaptive management framework.

Example 7: The importance of monitoring in adaptive management 
West et al. (2017) conducted a trial reintroduction of 16 captive warru (Petrogale lateralis) to test whether it was feasible to establish reintroduced populations. Monitoring the survival of individuals in reintroduced populations was crucial to tracking management success and facilitating further iterations of the adaptive management cycle. Importantly, they identified a period of high mortality in the three months immediately post-release and recommended intensive monitoring during this period for future releases.

\section{Example 8: Genetic monitoring and evaluation of plant translocations}

It is important to assess the genetic diversity of reintroduced populations. Kraus et al. (2002) assessed the genetic diversity of translocated populations of the endangered Corrigin grevillea (Grevillea scapigera). They demonstrated a failure to maintain genetic fidelity of propagules resulting in significantly less genetic diversity in the translocated population than was possible from original seed collections. This discovery was subsequently addressed in later translocations.

Example 9: Genetic monitoring and evaluation of animal translocations

Ottewell et al. (2014) evaluated the genetic diversity of golden bandicoots (Isoodon auratus) that were translocated from a large island source population to two other island sites and a mainland fenced enclosure. Their assessment indicated that the population currently has adequate diversity due to a large founder population and high reproductive rates. However, ongoing augmentation will be required to prevent genetic erosion in the long-term. Timely evaluation can enable early intervention before it is too late, or becomes more resource intensive.

Example 10: The value of monitoring for learning from failure A trial release of the endangered captive-bred woma pythons (Aspidites ramsayi), into the exotic-predatorfree Arid Recovery Reserve in northern South Australia ended within four months, with all of the reintroduced womas unexpectedly killed by mulga snakes (Pseudechis australis) - confirmed or implied in all cases (Read et al., 2011). Lessons learned included the need for conditioning of captive-bred snakes for wild release and the role of the mulga snake in structuring Australian arid-zone snake assemblages.

\section{Program evaluation and revision}

Example 11: Critical evaluation of current management actions to identify shortcomings

The critically endangered orange-bellied parrot is on the verge of extinction in the wild, with only three wildbred females returning to the breeding area in 2016-17 (supplemented by release of captive-bred birds). Stojanovic et al. (2017) critically evaluated existing recovery actions for this species and identified 10 new or varied actions for urgent implementation aimed at preventing extinction of the species. These focused primarily on improving quality and availability of wild foods and more intensively managing the wild population, especially during nesting.

Example 12: Identifying key drivers of success

Moseby et al. (2011) assessed the effectiveness of 10 reintroduction attempts in and around the Arid Recovery Reserve in northern South Australia between 1998 and 2008. Five locally-extinct mammal species and one reptile species were reintroduced into a fenced Reserve where cats (Felis catus), red foxes (Vulpes vulpes) and rabbits (Oryctolagus cuniculus) were excluded. Reintroductions of the greater stick-nest rat (Leporillus conditor, vulnerable), burrowing bettong (Bettongia lesueur, vulnerable), greater bilby (Macrotis lagotis, vulnerable) and western barred bandicoot (Perameles bougainville, endangered) were all considered successful because of population establishment, continued survival after eight years, increased distribution across the Reserve, and population persistence during a drought event. The trial reintroductions of the numbat (Myrmecobius fasciatus, vulnerable) and woma python (Aspidites ramsayi, endangered) into the Reserve were unsuccessful due to predation by native avian and reptilian predators respectively. The reintroduction of the greater bilby and burrowing bettong to outside of the Reserve was also unsuccessful. Assessment of the program has enabled Arid Recovery to prioritise efforts, secured ongoing funding through demonstrated effectiveness, and prompted a rethink of how to address ineffective management strategies.

Example 13: Analysing long-term monitoring data to assess effectiveness of management actions Walsh et al. (2012) analysed long-term monitoring data to evaluate the effectiveness of red fox (Vulpes vulpes) baiting as a management strategy for the vulnerable malleefowl (Leipoa ocellata). Unexpectedly, fox baiting was found to have little-to-no effect on malleefowl persistence, despite it being the preferred management strategy for this species. This example demonstrates the need to evaluate management effectiveness and the value of monitoring data for assessing progress towards management objectives.

Example 14: Identifying accountability for species trajectories 
The south-eastern Australian red-tailed black-cockatoo (Calyptorhynchus banksii graptogyne, endangered) recovery plan highlights threats to the cockatoo's food supplies and nesting habitats and identifies strategies for minimising the scale and risk of each threat (Department of Environment and Water Resources, 2007). The strategies identified also indicate where accountabilities lie to ensure that protective measures are put in place. These strategies include fire management planning to minimise crown scorch to stringybark trees thereby limiting losses of seed crops which the cockatoos depend upon. The strategies also include improvements to local planning controls over vegetation clearance applications to ensure protection of cockatoo nest trees and important feeding habitat.

\section{Stakeholder engagement and communication}

\section{Example 15: Importance of involving all stakeholders}

The critically endangered Lord Howe island stick insect (Dryococelus australis) conservation program provides an example of involving all stakeholders to ensure good outcomes (Carlile et al., 2009). Early and ongoing engagement with the local community meant that a proposed ship rat (Rattus rattus) eradication program was well-supported and implemented. Involvement with experts from Melbourne Zoo further enabled the development of appropriate husbandry procedures for the survival of captive bred individuals.

Example 16: Indigenous landowner engagement and decision making

An innovative conservation program for the vulnerable warru (Petrogale lateralis) on Anangu Pitjantjatjara Yankunytjatjara Lands has focused on improving in-situ survival and recruitment of warru (Read et al., 2018). Management has been led by Indigenous Warru Rangers in partnership with researchers and state government agencies. Management has focused on targeted removal of feral cats (Felis catus) and red foxes (Vulpes vulpes), management of invasive buffel grass (Cenchrus ciliaris), and establishing a captive breeding program. On-ground management occurs entirely on Indigenous lands, and Indigenous stakeholders are heavily involved in planning, management and strategic decision-making.

\section{Leadership and personnel}

\section{Example 17: Building strong collaborations in with partners}

The critically endangered spiny daisy (Acanthocladium dockeri) in South Australia has a small, but strong, recovery team that has achieved consistent and effective progress on implementation of its recovery plan (Clarke et al., 2013). The team consists of a mix of landholders, local industry and local and State Government representatives. The plan has had a sound research base from the time of the species rediscovery and has strong buy in from landholders and local industry.

Example 18: The need to commence management despite an initial lack of knowledge Aerial application of phosphite to protect highly susceptible threatened plants from Phytophthora cinnamomi has been implemented since 1997, despite initial concerns about phytotoxicity and cumulative impacts over time, with the rapid decline and local extinction of a number of plant species now halted and stabilised (Barrett and Yates, 2015). The early and successful application of phosphite has had major conservation benefits and highlights the value of decisive leadership in urgent situations.

Example 19: The need for recovery teams to incorporate a broad range of skillsets

The recovery team for the critically endangered southern and northern corroboree frogs (Pseudophryne corroboree and $P$. pengilleyi) consists of a diverse range of government practitioners, field ecologists, evolutionary biologists, disease biologists and zoo practitioners (McFadden et al., 2013). The diversity of team members has been crucial for the development of innovative solutions to achieve successful captive breeding of the species and to develop and trial new reintroduction techniques to re-establish wild populations. A range of skillsets has been particularly important in responding to a novel, emerging threat (chytrid fungus) that is highly challenging to manage.

728 Auld, T.D., Scott, J., 2013. Integrating fire management into conservation actions for the 
Barrett, S., Yates, C.J., 2015. Risks to a mountain summit ecosystem with endemic biota in southwestern Australia. Austral Ecol. 40, 423-432.

Benshemesh, J., Southwell, D.M., Lahoz-Monfort, J.J., Hauser, C., Rumpff, L., Bode, M., Burnard, T., Wright, J., Wintle, B.A., 2018. The national malleefowl monitoring effort: citizen scientists, databases and adaptive management, in: S., L., Lindenmayer, D.B., Robinson, N.M., Scheele, B.C., Southwell, D.M., Wintle, B.A. (Eds.), Monitoring threatened species and ecological communities. CSIRO Publishing, Melbourne.

Bode, M., Baker, C.M., Benshemesh, J., Burnard, T., Rumpff, L., Hauser, C.E., LahozMonfort, J.J., Wintle, B.A., 2017. Revealing beliefs: using ensemble ecosystem modelling to extrapolate expert beliefs to novel ecological scenarios. Methods in Ecology and Evolution 8, 1012-1021.

Canessa, S., Converse, S.J., West, M., Clemann, N., Gillespie, G., McFadden, M., Silla, A.J., Parris, K.M., McCarthy, M.A., 2016. Planning for ex situ conservation in the face of uncertainty. Conserv. Biol. 30, 599-609.

Carlile, N., Priddel, D., Honan, P., 2009. The recovery programme for the Lord Howe Island Phasmid (Dryococelus australis) following its rediscovery. Ecol. Manage. Restor. 10, S124S128.

Clarke, A., Robertson, M.A., Pieck, A., 2013. Recovery Plan for Acanthocladium dockeri (Spiny Daisy) 2013. Department of Environment, Water and Natural Resources, Clare, South Australia.

Department of Environment and Water Resources, 2007. National Recovery Plan for the South-eastern Australian Red-tailed Black-Cockatoo (Calyptorhynchus banksia graptogyne). Canberra; pp. 19.. http://www.redtail.com.au/uploads/file/c-b-graptogyne.pdf.

Krauss, S.L., Dixon, B., Dixon, K.W., 2002. Rapid genetic decline in a translocated population of the endangered plant Grevillea scapigera. Conserv. Biol. 16, 986-994.

McFadden, M., Hobbs, R., Marantelli, G., Harlow, P., Banks, C., Hunter, D., 2013. Captive management and breeding of the critically endangered southern corroboree frog (Pseudophryne corroboree)(Moore 1953) at Taronga and Melbourne Zoos. Amphibian \& Reptile Conservation 5, 70-87. 

evolutionary history of threatened plant and insect populations warrant unified conservation management approaches. Biol. Conserv. 198, 135-144. the outcome of 10 reintroduction attempts in arid South Australia. Biol. Conserv. 144, 28632872.

Ottewell, K., Dunlop, J., Thomas, N., Morris, K., Coates, D., Byrne, M., 2014. Evaluating success of translocations in maintaining genetic diversity in a threatened mammal. Biol. Conserv. 171, 209-219.

Rathbone, D.A., Barrett, S., 2017. Vertebrate browsing impacts in a threatened montane plant community and implications for management. Ecol. Manage. Restor. 18, 164-171. back warru: return of the black-footed rock-wallaby to the APY Lands, in: Garnett, S., Latch, P., Lindenmayer, D.B., Woinarski, J. (Eds.), Recovering Australian threatened species: a book of hope. CSIRO Publishing, Victoria.

Read, J., Johnston, G., Morley, T., 2011. Predation by snakes thwarts trial reintroduction of the endangered woma python Aspidites ramsayi. Oryx 45, 505-512.

Stojanovic, D., Alves, F., Cook, H., Crates, R., Heinsohn, R., Peters, A., Rayner, L., Troy, S.N., Webb, M.H., 2017. Further knowledge and urgent action required to save Orangebellied Parrots from extinction. Emu-Austral Ornithology, 1-9. invasive predator control: the importance of evaluating conservation management actions. Anim. Conserv. 15, 319-328.

West, R., Read, J.L., Ward, M.J., Foster, W.K., Taggart, D.A., 2017. Monitoring for adaptive management in a trial reintroduction of the black-footed rock-wallaby Petrogale lateralis. Oryx 51, 554-563. 